\title{
Análise discente da contribuição do preceptor e do estágio na formação do aluno de graduação da FO UERJ
}

\author{
Maria Isabel de Castro de Souza*, Katlin Darlen Maia**, Renata Rocha Jorge***, Teresa \\ Berlink****, Maria Eliza Barbosa Ramos***** \\ * Vice-Diretora da FO-UERJ \\ ** Professora Adjunta das Disciplinas de Saúde Bucal Coletiva - UERJ \\ *** Professora Adjunta das Disciplinas de Saúde Bucal Coletiva - UERJ \\ **** Coordenadora Adjunta de Ensino de Graduação da FO-UERJ \\ ***** Coordenadora de Ensino de Graduação da FO-UERJ
}

\section{RESUMO}

O objetivo deste estudo foi analisar o impacto da contribuição do preceptor e do estágio na rede pública na formação dos alunos de graduação da Faculdade de Odontologia da UERJ, através do programa Pró-Saúde. Foram analisados 95 questionários de avaliação que são distribuídos aos alunos ao final do período no qual constam as avaliações da contribuição do preceptor durante a formação do aluno, a contribuição do estágio em serviço na formação do aluno, os pontos positivos, pontos negativos e sugestões. Através das respostas obtidas podemos concluir que a realização do estágio com o suporte do preceptor aparece como recurso que contribui para ampliar a experiência e vivência do aluno, oportunizando uma aproximação significativa entre os alunos e o Sistema Único de Saúde, assim como é importante o estabelecimento da integração entre academia e serviço para o desenvolvimento de mecanismos de capacitação dos profissionais da rede através dos projetos públicos vigentes.

\section{DESCRITORES}

Preceptor. Educação em saúde. Prática de ensinoaprendizagem.

$\Delta$ s últimas décadas foram marcadas por mudanças significativas dentro das Instituições de Ensino Superior (IES), principalmente no que se refere ao ensino de graduação da área da Saúde. As políticas públicas promovidas, conjuntamente, pelo Ministério da Saúde (MS) e Ministério da Educação (ME), têm demonstrado uma especial preocupação na re- formulação e re-condução da formação dos profissionais que, todo ano, ingressam no mercado de trabalho, encontrando, muitas das vezes, realidades diferentes daquelas vividas dentro da faculdade que cursou.

Com o intuito de fortalecer o compromisso social das IES e preparar os novos profissionais para a realidade da demanda populacional o MS e ME desenvolveram diferentes projetos como, por exemplo, PROMED, Telessaúde, PET Saúde, UNA-SUS e PróSaúde, bem como a consolidação das novas Diretrizes Curriculares Nacionais (DCN's), em articulação com as entidades de ensino das áreas da saúde. ${ }^{1,4}$

O objetivo principal das DCN's é o de estabelecer novas formas de organização curricular, articular ensino e rede, redimensionando o status do processo educativo e prática em saúde. Na Odontologia, as diretrizes determinam que o perfil deste novo profissional deverá ser generalista, com visão humanista, crítica e reflexiva, capacitado a atuar em todos os níveis de atenção à saúde, com base no rigor técnico e científico, bem como ser capacitado ao exercício de atividades referentes à saúde bucal da população, pautado em princípios éticos, legais e na compreensão da realidade social, cultural e econômica do seu meio, dirigindo sua atuação para a transformação da realidade em benefícios da sociedade. ${ }^{2,3}$

Com a determinação de incentivar mudanças na formação profissional, não mais em uma lógica de informações fragmentadas e sim através de um processo de conhecimento investigativo e do contato com o real na perspectiva da mudança social, o MS e ME lançaram edital público em dezembro de 2007 
(Pró-Saúde) que tinha como estratégia de implementação a proposta de uma maior articulação entre as Instituições de Ensino Superior e o serviço público de Saúde. Os processos de reorientação da formação no Pró-Saúde estruturam-se em três eixos de transformação:

1. Orientação teórica;

2. Cenários de Prática e;

3. Orientação Pedagógica. ${ }^{1,4}$

Neste aspecto, um dos eixos do processo de reorientação se tornou primordial na formação dos novos profissionais e na articulação entre academia e serviço: a diversificação dos cenários de prática e, sendo assim, o preceptor apresenta um papel de destaque.

Na prática, não é a simples alocação do horário do aluno em local específico dentro da rede pública que determinará uma melhoria da capacitação profissional e atendimento ao usuário, mas sim a integração do conhecimento aliado a capacidade de problematização, e sua transposição para o ambiente de prática do aluno. Além disso, o aluno é apresentado ao serviço sem que o preceptor tenha sido capacitado também para exercer tal função, o que leva a um choque de informações e exposições de ambas as partes (academia e serviço). ${ }^{5}$

Este trabalho teve como objetivo fazer uma análise qualitativa do papel do preceptor e do estágio na rede, pela ótica do aluno, sobre a formação de alunos do último período de graduação da Faculdade de Odontologia da UERJ através do Pró-Saúde.

\section{MATERIAIS E MÉTODOS}

Foram utilizados para este estudo um total de 95 questionários, respondidos por alunos de graduação que cursaram oúltimo período curricular ( $8^{\circ}$ período), nos anos de 2008 (24 alunos, segundo semestre), 2009 (23 alunos, primeiro semestre, e 19 alunos, segundo semestre) e 2010 (29 alunos, primeiro semestre).

Todo início de semestre os alunos recebem, duran- te aula inaugural da Disciplina de Saúde Bucal Coletiva III, informações sobre as atividades que exercerão nos diferentes cenários de prática, bem como orientações sobre os itens que constarão na avaliação final do estágio. Esta avaliação é uma atividade obrigatória curricular, onde os alunos respondem ao questionário denominado Roteiro de Avaliação Final do Estágio do Aluno.

Os cenários utilizados estão inseridos na CAP 2.2, área geográfica onde se encontra a FOUERJ e foram os seguintes:

- PAM Helio Pellegrino,

- PAM Heitor Beltrão,

- Hospital Municipal Jesus,

- CMS Maria Augusta Estrella e

- IOC.

Com o intuito de se realizar a avaliação para o presente estudo, foram selecionadas as seguintes questões abertas do Roteiro de Avaliação utilizado pela Disciplina de Saúde Bucal Coletiva III:

1. Avalie a contribuição do preceptor durante sua formação

2. Avalie a contribuição do estágio em serviço à sua formação

3. Pontos positivos do estágio

4. Pontos negativos do estágio

5. Sugestões

A análise temática foi empregada neste trabalho por permitir descobrir os núcleos dos sentidos que compõem uma comunicação, cuja freqüência signifique alguma coisa para o objeto analítico visado. Estes temas denotam os valores de referência e os modelos de comportamento presentes nos discursos. Para análise dos dados, todas as respostas abertas foram analisadas agrupando-se as opiniões em categorias mencionadas pelos respondentes.

\section{RESULTADOS}

Vejam os resultados nas Tabelas de 1 a 5:

Tabela 1 - Compilação das respostas dos alunos da questão sobre contribuição do preceptor durante sua formação.

\begin{tabular}{|c|c|c|c|}
\hline $2008 / 2$ & $2009 / 1$ & $2009 / 2$ & $2010 / 1$ \\
\hline $\begin{array}{l}\text { - Relevante } \\
\text { - Rica troca de informações } \\
\text { - Fundamental na inserção } \\
\text { do aluno } \\
\text { - Oportunizou o atendimento } \\
\text { aos pacientes }\end{array}$ & $\begin{array}{l}\text { - Relevante } \\
\text { - Ampliação na capacidade } \\
\text { de propostas de tratamento }\end{array}$ & $\begin{array}{l}\text { - Auxilio na resolução de } \\
\text { problemas do cotidiano } \\
\text { - Demonstração da rotina de } \\
\text { atendimento e tratamento } \\
\text { que leva em consideração o } \\
\text { contexto do paciente } \\
\text { - Conhecimento de outras } \\
\text { técnicas }\end{array}$ & $\begin{array}{l}\text { - Observação sobre as } \\
\text { condutas negativas do } \\
\text { preceptor } \\
\text { - Novos conhecimentos }\end{array}$ \\
\hline
\end{tabular}


Tabela 2 - Compilação das respostas dos alunos da questão sobre contribuição do estágio durante sua formação.

\begin{tabular}{|c|c|c|c|}
\hline $2008 / 2$ & $2009 / 1$ & $2009 / 2$ & 2010/1 \\
\hline $\begin{array}{l}\text { - Proporciona experiências } \\
\text { diferentes da faculdade } \\
\text { - Vivência no setor público } \\
\text { - Visão maior sobre a } \\
\text { odontologia fora da } \\
\text { faculdade } \\
\text { - Agilidade em atendimento } \\
\text { clínico } \\
\text { - Contato com pacientes } \\
\text { diferentes } \\
\text { - Vivência no acolhimento } \\
\text { - Entender e poder resolver o } \\
\text { problema de cada paciente } \\
\text { - Aprender como funciona o } \\
\text { serviço público em nosso } \\
\text { país } \\
\text { - Observar as necessidades } \\
\text { da população em termos de } \\
\text { assistência básica e saúde } \\
\text { bucal }\end{array}$ & $\begin{array}{l}\text { - Prática clínica } \\
\text { - Será agente facilitador se } \\
\text { quiser ingressar na rede } \\
\text { - Entendimento de uma } \\
\text { unidade básica de saúde e } \\
\text { vivência clínica constatando } \\
\text { haver um serviço de } \\
\text { qualidade } \\
\text { - Aplicação da teoria da } \\
\text { faculdade na prática clínica } \\
\text { - Visualização do sistema de } \\
\text { saúde } \\
\text { - Experiências não } \\
\text { vivenciadas na faculdade } \\
\text { - Observação das demandas } \\
\text { da população em relação a } \\
\text { saúde bucal }\end{array}$ & $\begin{array}{l}\text { - Prática clínica } \\
\text { - Considerou um local bom } \\
\text { para trabalhar futuramente } \\
\text { - Aprender a trabalhar com } \\
\text { sala de espera e trabalhar } \\
\text { em equipe } \\
\text { - Contato com desafios } \\
\text { clínicos (muito } \\
\text { enriquecedor) } \\
\text { - Aprender a interagir com } \\
\text { diferentes pacientes e a } \\
\text { importância de trabalharmos } \\
\text { com promoção de saúde } \\
\text { - Trabalhar com mais } \\
\text { confiança } \\
\text { - Despertar da } \\
\text { responsabilidade social } \\
\text { - Formação mais completa } \\
\text { - Aprender a lidar com a } \\
\text { realidade de materiais e } \\
\text { pacientes fora da faculdade }\end{array}$ & $\begin{array}{l}\text { - Enriquecedor } \\
\text { - Contato com a realidade do } \\
\text { serviço } \\
\text { - Visão mais realista do } \\
\text { serviço } \\
\text { - Maior responsabilidade } \\
\text { com a profissão e com o } \\
\text { paciente } \\
\text { - Atendimento a vários tipos } \\
\text { de pacientes } \\
\text { - Percepção real do mercado } \\
\text { de trabalho }\end{array}$ \\
\hline
\end{tabular}

Tabela 3 - Compilação das respostas dos alunos da questão sobre os pontos positivos do estágio.

\begin{tabular}{|c|c|c|c|}
\hline $2008 / 2$ & $2009 / 1$ & $2009 / 2$ & $2010 / 1$ \\
\hline $\begin{array}{l}\text { - Boa relação com preceptor } \\
\text { - Experiência } \\
\text { - Ganho na prática } \\
\text { - Conhecimento da rede } \\
\text { - Contato com o usuário }\end{array}$ & $\begin{array}{l}\text { - Conhecimento da rede } \\
\text { - Envolvimento com a } \\
\text { sociedade } \\
\text { - Experiência clínica } \\
\text { - Experiência em possível } \\
\text { local de trabalho } \\
\text { - Agilidade } \\
\text { - Aperfeiçoamento profissional } \\
\text { - Aprimoramento de técnicas } \\
\text { - Conhecimento do sistema } \\
\text { de referência e contra- } \\
\text { referência }\end{array}$ & $\begin{array}{l}\text { - Conhecimento sobre } \\
\text { atenção básica } \\
\text { - Maior agilidade de } \\
\text { atendimento } \\
\text { - Convívio com outros } \\
\text { profissionais } \\
\text { - Experiência em trabalhar } \\
\text { na rede }\end{array}$ & $\begin{array}{l}\text { - Prática clínica, } \\
\text { - Saber mais sobre a } \\
\text { demanda da população } \\
\text { - Mais agilidade } \\
\text { - ampliou conhecimento } \\
\text { - Ter acesso a outras } \\
\text { opiniões científicas } \\
\text { - Tomada de decisão }\end{array}$ \\
\hline
\end{tabular}

Tabela 4 - Compilação das respostas dos alunos da questão sobre os pontos negativos do estágio.

\begin{tabular}{|c|c|c|c|}
\hline $2008 / 2$ & $2009 / 1$ & $2009 / 2$ & $2010 / 1$ \\
\hline $\begin{array}{l}\text { - Dificuldade de locomoção } \\
\text { entre os estágios } \\
\text { - Burocracia de } \\
\text { regulamentação do estágio } \\
\text { - Horário } \\
\text { - Falta de material adequado } \\
\text { - Atualização dos } \\
\text { profissionais da rede } \\
\text { - Qualidade do material } \\
\text { utilizado } \\
\text { - Concentração de } \\
\text { profissionais em um } \\
\text { mesmo dia } \\
\text { - Baixa quantidade de } \\
\text { pacientes } \\
\text { - Ausência RX no consultório }\end{array}$ & $\begin{array}{l}\text { - Não atende a demanda da } \\
\text { - População } \\
\text { - Poucas horas na semana } \\
\text { - Número de professores no } \\
\text { local reduzido } \\
\text { - Falta de material } \\
\text { - Visão do profissional da } \\
\text { rede em relação ao aluno }\end{array}$ & $\begin{array}{l}\text { - Ausência do preceptor, } \\
\text { - Atraso dos profissionais no } \\
\text { atendimento dos pacientes } \\
\text { - Conflito entre chefias e } \\
\text { profissionais } \\
\text { - Falta de material }\end{array}$ & $\begin{array}{l}\text { - Falta de tempo do } \\
\text { preceptor para atender ao } \\
\text { aluno } \\
\text { - Dificuldade de } \\
\text { comunicação com os } \\
\text { preceptores } \\
\text { - Preceptores não receptivos } \\
\text { - Falta de material } \\
\text { - Falta de comprometimento } \\
\text { do profissional da rede com } \\
\text { o usuário }\end{array}$ \\
\hline
\end{tabular}


Tabela 5 - Compilação das respostas dos alunos da questão sobre as sugestões.

\begin{tabular}{|c|c|c|c|}
\hline $2008 / 2$ & $2009 / 1$ & $2009 / 2$ & $2010 / 1$ \\
\hline $\begin{array}{l}\text { - Todos os alunos devem } \\
\text { passar por esta experiência } \\
\text { - Discutir a entrada dos } \\
\text { alunos no serviço com os } \\
\text { dentistas da rede } \\
\text { - Colocar estágios nos CEO's } \\
\text { - adequação dos horários } \\
\text { entre posto e faculdade } \\
\text { - Presença dos professores } \\
\text { no campo de estágio }\end{array}$ & $\begin{array}{l}\text { - Atuação dos alunos desde } \\
\text { períodos mais precoces } \\
\text { - Melhorias no acolhimento } \\
\text { do usuário } \\
\text { - Aparelho de Rx na atenção } \\
\text { básica } \\
\text { - Capacitação para os } \\
\text { profissionais } \\
\text { - Melhorias estruturais das } \\
\text { unidades } \\
\text { - Contratação de profissionais } \\
\text { técnicos (TSB e ASB) } \\
\text { para auxiliar e melhorar o } \\
\text { atendimento clínico }\end{array}$ & $\begin{array}{l}\text { - Capacitação dos } \\
\text { profissionais da rede } \\
\text { - Estágio em unidades } \\
\text { hospitalares } \\
\text { - Iniciar o estágio mais cedo } \\
\text { na faculdade } \\
\text { - Aumento do tempo de } \\
\text { estagio } \\
\text { - Aquisição de aparelho } \\
\text { de Rx }\end{array}$ & $\begin{array}{l}\text { - Maior número de locais } \\
\text { para melhor dividir os } \\
\text { alunos } \\
\text { - Capacitação dos } \\
\text { preceptores } \\
\text { - Mais tempo para o estágio } \\
\text { - Fazer seleção de } \\
\text { preceptores }\end{array}$ \\
\hline
\end{tabular}

\section{DISCUSSÃO}

As perguntas abertas permitem aos participantes explanarem livremente sobre os temas propostos, e constitui um momento de muito aprendizado e, muitas vezes, até de desabafo. O que tornou as interpretações algo mais familiar foi o fato das pesquisadoras serem parte integrante do processo. Tal fato permitiu pensar, à luz da experiência, de estar no campo e presenciar o desenrolar dos eventos, em oposição a uma concepção de pesquisa em que se relata ou analisa situações das quais os autores desconheçam. Esta percepção tornou o produto final mais aproximado da realidade.

A grande maioria dos alunos determinou ser muito importante o papel e contribuição do preceptor em sua formação profissional, muito embora uma das sugestões mais apontadas tenha sido a capacitação dos mesmos, tanto no acolhimento dos alunos quanto a questão técnica e conhecimento científico. Isto pode indicar que a utilização das políticas públicas de capacitação para estes profissionais como o Telessaúde e UNA-SUS bem como, a aproximação da academia ao serviço (Pró-Saúde), deverão promover um impacto profundo na transformação deste cenário. Sob este aspecto podemos destacar o Eixo 1 (Orientação Teórica) do Pró-Saúde que aponta como exemplo de objetivos a atenção especial à educação permanente, não restrita à pós-graduação especializada e a orientação sobre melhores práticas gerenciais que facilitem o relacionamento.

Alguns autores na literatura descrevem que é essencial para a mudança na orientação pedagógica capacitar docentes em novas metodologias de ensinoaprendizagem, criar a figura do preceptor e ampliar laboratórios de práticas profissionais. Todas essas ações visam à integração entre os ciclos básico e clí- nico, redirecionando o foco para a Atenção Primária à Saúde e para as estratégias de Educação Permanente como formas de preparar o pessoal docente e dos serviços que recebem os estudantes. ${ }^{6-8}$

Outros autores descrevem ainda que o preceptor tem papel importante na formação do aluno porque realiza uma atividade de ensino, mas que como tal não é considerada. Não existe capacitação específica para relação profissional-aluno que aí se constrói, nem compromisso formal com a formação. Além disso, os estudos sobre este assunto ainda são muito tímidos, propondo uma formulação e implementação de processos educativos na formação destes profissionais de saúde. Os alunos ficam "jogados" nos serviços e, sem uma adequada preceptoria, acabam expostos à má prática, são desatendidos, acabam "desaprendendo" e aumentando ainda mais a desilusão quanto ao trabalho na saúde pública e à realização das diretrizes do SUS. Sua função de mediador dos diferentes níveis de conhecimento aponta a necessidade de estabelecer relações pedagógicas, ou seja, relações que conduzem a aprendizagem prática do aluno, o "ser profissional da área de saúde". ${ }^{9-12}$

O principal papel das IES deve ser o de reconhecer e capacitar o profissional interessado na atividade de preceptoria para que ele desempenhe com segurança e competência o que, na sua própria visão, faz parte de suas atribuições. E isso precisa ser discutido no âmbito dos serviços de saúde e nas IES:

\footnotetext{
[...] os profissionais dos serviços valorizam, de forma geral, os estímulos com os alunos e os professores. Estes, quando realizam práticas nos novos cenários, também valorizam as experiências adquiridas como meios de adequação dos conteúdos curriculares, propiciados pela incorporação de
} 
temas/problemas com maior relevância. ${ }^{13}$

Ao analisarmos as respostas sobre a contribuição do estágio na formação profissional dos alunos, pontos positivos e pontos negativos, novamente, a relevância desta experiência é destacada. Neste caso, podemos observar que os três eixos de transformação na reorientação profissional são contemplados:

- observação dos determinantes de saúde (biológicos e sociais da doença);

- avaliação crítica do processo de Atenção Básica;

- aprender fazendo e com sentido crítico na análise da prática clínica;

- o eixo do aprendizado deve ser a própria atividade dos serviços;

- ênfase no aprendizado baseado na solução de problemas, avaliação formativa e somativa;

- diversificação de cenários;

- trabalho com o sistema de referência e contrareferência;

- interação entre comunidade e alunos, e

- importância do trabalho conjunto das equipes multiprofissionais..$^{14-16}$

Além disso, tais pressupostos indicam uma mudança significativa nos conceitos destes profissionais, que ingressarão no mercado de trabalho, sobre a importância do serviço público, seu impacto sobre a população e, sua responsabilidade não só profissional como também social. Sob esta ótica podemos destacar observação de Stella (1999), concluindo em seu trabalho que os profissionais formados não atendem as necessidades de saúde no Brasil. As escolas possuem currículos e carga teórica extensa e, não preparam os alunos para atuarem na atenção primária e secundária, com um leque não aprofundado de conhecimentos das especialidades. ${ }^{16,17}$

Uma resposta em especial chamou atenção quando o discente respondeu:

\footnotetext{
"Pude conhecer melhor a realidade do que é o SUS. Um sistema ótimo mas que para que funcione as partes precisam estar comprometidas diferente de ter um compromisso."
}

Muitos alunos ainda descreveram como ponto importante às condições de infra-estrutura, que também precisam ser adequadas para o acolhimento do estudante. O reduzido espaço e as precárias condições físicas foram apontados tanto na pergunta sobre as dificuldades quanto nos pontos negativos.

Apesar de existirem muitas correções a serem fei- tas nesta ferramenta utilizada no processo de formação profissional, pode-se observar que a grande maioria dos alunos não só descreveu a experiência do estágio como um divisor de águas em sua capacitação como também sugeriu o aumento da carga horária empregada bem como a inserção desta experiência em outros períodos do currículo. ${ }^{18}$

\section{CONCLUSÃo}

Após a análise qualitativa das respostas podemos concluir neste estudo que:

1. A realização do estágio com o suporte do preceptor, aparece como recurso que contribui para ampliar a experiência e vivência do aluno, oportunizando a aquisição de novos conhecimentos, que terão aplicabilidade na prática diária do futuro profissional.

2. Percebe-se que esta atividade gerou uma aproximação significativa entre os alunos e o Sistema Único de Saúde, podendo, tal fato, contribuir para melhor compreensão do mesmo e atuação mais eficiente.

3. É dever das IES estabelecer uma interlocução positiva entre o serviço e os futuros profissionais de saúde bem como desenvolver mecanismos de capacitação/atualização dos preceptores, utilizando os projetos públicos vigentes (PROMED, PróSaúde, UNA-SUS, PET Saúde).

\section{ABSTRACT}

Student assessment of the contribution of the instructor and internship to the training of undergraduate students at FO UERJ

The aim of this study was to analyze how the instructor and internship in the public healthcare system contribute to impacting the academic training of undergraduate students from the School of Dentistry, State University of Rio de Janeiro, through the "PróSaude" program. An analysis was made of 95 evaluation questionnaires usually distributed to undergraduate students at the end of their academic term. These questionnaires evaluate the contribution of the instructor and of the service-providing internship to the student's undergraduate training, both positive and negative aspects of the experience, and also garner suggestions. According to the replies obtained, we can conclude that the internship given with the support of the instructor was rated as a resource that contributes to broadening the student's experience. Moreover, this internship offers students a greater opportunity to develop a closer relationship with the 
SUS (Brazilian Unified Healthcare System), and to establish greater integration between academia and service-rendering to foster the development of training mechanisms for public healthcare professionals through the public projects currently in place.

\section{DESCRIPTORS}

Instructor. Health education. Teaching-learning practice.

\section{REFERÊNCIAS}

1 Brasil. Ministério da Saúde. Portaria 198/GM/MS. Diário Oficial da União nº 32/2004, Secção I. Brasil. Ministério da Saúde. Pró-saúde: programa nacional de reorientação da formação profissional em saúde /Ministério da Saúde, Ministério da Educação. Brasília: Ministério da Saúde; 2005. 77 p. (Série C. Projetos, Programas e Relatórios).

2 Brasil. Ministério da Educação. Conselho Nacional de Educação. Resolução CNE/CES n ${ }^{\circ} 4$, de 07/11/2001. Diretrizes Curriculares Nacionais do Curso de Graduação em Medicina. Brasília: Câmara de Educação Superior; 2001.

3 Bagnato M. Inovações Pedagógicas na Educação Superior em Saúde: algumas reflexões. 2005. Disponível < mbagnato@unicamp.br > PRAESA-Laboratório de Estudos e Pesquisas em Práticas de Educação e Saúde. Acesso em: 13 out. 2008.

4 Brasil. Ministério da Saúde. Pró-saúde: programa nacional de reorientação da formação profissional em saúde /Ministério da Saúde, Ministério da Educação. Brasília: Ministério da Saúde; 2005. 77 p. (Série C. Projetos, Programas e Relatórios).

5 Botti SHO, Rego S. Preceptor, supervisor, tutor e mentor: quais são seus papéis? Revista Brasileira de Educação Médica. 32 (3):363-373;2008.

6 Missakal, H, Ribeiro VMB. Preceptoria na formação médica: subsídios para integrar teoria e prática na formação profissional - o que dizem os trabalhos nos congressos. VII Enpec Encontro Nacional de Pesquisa em Educação em Ciências, 8 de novembro de 2009.

7 Almeida M, Feurwerker L, Llanos M. A educação dos profissionais de saúde na América Latina: teoria e prática de um movimento de mudança. São Paulo: Hucitec/ Buenos Aires: Lugar Editorial/ Londrina:Editora UEL; 1999.

8 Cunha MI. Inovações pedagógicas: tempos de silêncios e possibilidades de mudanças. Interface Comun Saúde Educ 2003;7(13):149-52.

9 Sambunjak D, Straus SE, Marusic A. Mentoring in academic medicine - a systematic review. JAMA 2006; 296(9):1103-1115.

10 Tsai JC, Lee PP, Chasteen S, Taylor RJ, Brennan MW, Schmidt GE. Resident physician mentoring program in ophthalmology: the Tennessee experience. Arch Ophthalmol 2006;124: 264267.

11 Wullaume SM, Batista NA. O Preceptor na residência médica em Pediatria: principais atributos. Jornal de Pediatria 2000; 76 (5):333-338.

12 Souza AM de A, Galvão E de A, Santos I dos, Roschke MAC. Processo educativo nos serviços de saúde. Brasília (DF): OPAS; 1991. [Série Desenvolvimento de Recursos Humanos, 1]

13 Trajman A, Assunção N, Venturi M, Tobias D, Toschi W, Brant V.A preceptoria na rede da Secretaria Municipal de Saúde do Rio de Janeiro: opinião dos profissionais de Saúde. Rev Brás Educ Méd. 2009; 33 (1): 24 - 32.

14 Batista $\mathrm{N}$ et al. Problem-solving approach in the training of healthcare Professional. Rev Saúde Pública 2005; 39(2) 1-7.

15 Colliver JA. Effectiveness of problem-based learning curricula: research and theory. Acad Med 2000;75:259-66.

16 Abreu Neto, I. P. et al.. Percepção dos Professores sobre o Novo Currículo de Graduação da Faculdade de Medicina da UFG Implantado em 2003. Revista Brasileira de Educação Médica, Rio de Janeiro, v. 30, n. 3, p. 154-160,maio/ago.,2006. (http:// www.scielo.br/pdf/rbem/v30n3/05.pdf)

17 Araujo MNT. ARTICULAÇÃO COM A REDE BÁSICA DO SUS: CONSTRUÇÃO DE PARCERIA. Revista Brasileira de Educação Médica 2008; 32 (3):440, jul./set.

18 Stella R. O ensino médico precisa ser reformulado. Jornal MEDICINA, Brasília, CFM, 1999. 